\title{
GREGORIO SALVADOR, MAESTRO EN LA LAGUNA Y MÁS ALLÁ
}

Estamos en octubre de 1966. Mi promoción empezaba sus estudios en la Facultad de Filosofía y Letras de la Universidad de La Laguna, y don Gregorio Salvador Caja acababa de tomar posesión de su cátedra de Gramática Histórica en esta universidad.

Pudo haber sido un «ave de paso» más, como se denominaba, en aquellos tiempos, a los catedráticos peninsulares que aprobaban las oposiciones, obtenían una plaza en La Laguna y se marchaban a cualquier universidad de la Península en la primera ocasión que se les presentara. Y la oportunidad se le presentó al doctor Salvador, pues al año siguiente pudo optar a la cátedra de la Universidad de Salamanca, pero no lo hizo. Se quedó en Canarias durante nueve años, y esta presencia y permanencia influyeron significativamente en el vigor que aquí experimentaron los estudios de Dialectología, Semántica y Crítica Literaria. Los efectos de su marcha a la Universidad de Granada en 1975 quedaron mitigados porque ya se había consolidado la carrera docente e investigadora de sus primeros discípulos: Ramón Trujillo, el primero; poco después, Inmaculada Corrales y Antonio Lorenzo.

Mi promoción asistió a las primeras clases del doctor Salvador con una mezcla de temor inicial, que pronto desapareció, y de respeto y admiración, que no decayeron a lo largo de toda la carrera. De temor inicial, porque el grado de exigencia, de rigor y de profundidad que imprimió a la asignatura de Lengua Española obligaba a un esfuerzo muy superior al dedicado a otras materias. Su magisterio se prolongó a lo largo de toda la especialidad de Filología Románica a través de sus clases de Crítica Literaria, de Historia del Español y de Dialectología, y en estos años se consolidó aquel respeto y admiración anidados en el primer curso, hasta tal punto que, para sus alumnos más cercanos, don Gregorio siempre era aludido y evocado con la expresión antonomástica de «el Maestro», que conservó durante largo, muy largo tiempo.

Ejerció una gran influencia en la formación de sus alumnos, y quedó para siempre la honda huella de su competencia docente, de su gran capacidad para transmitir conocimientos y abrir el camino al análisis estructural de las lenguas funcionales del español y de la lengua histórica. A diario se ponían de manifiesto sus dotes de gran comunicador, compartiendo experiencias propias extraídas de su actividad como dialectólogo de campo, informando de novedades literarias o proporcionando técnicas de análisis de textos, que tanto se echaban en falta en las asignaturas de Literatura.

Llegó a La Laguna cuando por Europa empezaba a hablarse del estructuralismo, y puso tanto entusiasmo y mostró tanta pasión por las aportaciones de esta corriente a la Lingüística y a la Estilística, que sus alumnos acabamos convenci- 
dos de que el marco teórico y la metodología estructuralistas eran los caminos por donde habría de discurrir nuestra andadura como profesores e investigadores de la lengua y de la literatura.

De esas herramientas teóricas y metodológicas se nutrieron, nos nutrimos, todos aquellos alumnos que tuvimos la suerte de mantener con el Maestro un vínculo más allá de los estudios de licenciatura. Y creo no exagerar ni convertir en falsa laudatio esta sentida elegía si afirmo que no es concebible ni explicable la vitalidad, calidad y rigor de la posterior y actual investigación lingüística en las universidades de Canarias sin aquellos años en que el doctor Salvador animó, promocionó y dirigió tesinas y tesis doctorales sobre Dialectología, Semántica estructural y Crítica Literaria y Estilística.

Pero vida tan larga y fecunda no puede quedar limitada al recuerdo de sus nueve años de estancia en La Laguna. De aquí pasó a ocupar la cátedra de Gramática Histórica en la Universidad de Granada, y de allí marchó a Madrid. Había hecho su carrera universitaria en Granada, donde fue alumno y discípulo del doctor Alvar, con el que colaboró en la elaboración del $A L E A$, para el que realizó casi la mitad de las encuestas de campo fijadas para este primer Atlas Lingüístico y Etnográfico que se hizo en todo el mundo hispánico.

Con el magisterio del profesor Alvar y su participación activa en el $A L E A$, era esperable que su tesis se orientara hacia la Dialectología, como así fue. En 1957 se doctoró con El habla de Cúllar-Baza. No fue un trabajo dialectológico como los que hasta ese momento predominaban en las universidades europeas, que consideraban la Dialectología como una secuela de la Gramática Histórica y cuyo objetivo fundamental era una especie de búsqueda arqueológica de fósiles lingüísticos que documentaran fenómenos pertenecientes a pasados estados de lengua en cualquier territorio de la antigua Romania. La tesis del doctor Salvador, por el contrario, aportó novedades en planteamientos metodológicos y de enfoque, pues orientó su investigación a la descripción sincrónica del habla de esa localidad de la Andalucía oriental, bajo el principio saussureano de que todos los elementos de esa lengua están relacionados porque forman un sistema de dependencias mutuas.

Sin entrar en las valiosas conclusiones que su investigación revela, como el desdoblamiento vocálico en el andaluz oriental, lo verdaderamente trascendental es que su obra estableció las coordenadas de los más relevantes y solventes estudios posteriores de Dialectología: análisis descriptivo, sincrónico y estructural de un estado de lengua espacialmente delimitado. Esa línea investigadora inspiró sus posteriores estudios dialectales de fonética y fonología, de gramática y de semántica, como su análisis del campo semántico «Arar» en andaluz, o el descubrimiento de algunas oposiciones léxicas observadas en encuestas dirigidas por él, y analizadas y desarrolladas por Ramón Trujillo en su muy estimable trabajo Resultado de dos encuestas dialectales en Masca.

En ambos trabajos de semántica dialectal se vislumbran los planteamientos que muy pronto darían como resultado las investigaciones, bajo su dirección, sobre campos semánticos y que, por la dimensión y profundidad de sus resultados, dieron lugar, con el tiempo y con las aportaciones teóricas de sus continuadores, a lo que se conoció en los círculos académicos como la Escuela Semántica de La Laguna. 
Con el paso de los años, sobre todo a raíz de su incorporación a la Real Academia Española, el profesor Salvador mostró a través de libros, conferencias, comunicaciones en congresos y en artículos de prensa una apasionada, contundente y continuada defensa del español. Por su carácter combativo y polémico, nunca eludió el debate sobre las lenguas de Espańa, la convivencia de lenguas en comunidades con lengua propia, la utilización política de esta cuestión y los efectos perniciosos que ello ha estado produciendo en la legislación educativa. Nunca rehuyó hablar de estas cuestiones en cada ocasión que se le ofrecía, manifestando con frecuencia su irritación como hispanohablante y su indignación como lingüista ante lo que él consideraba «variopinto y carnavalesco espectáculo políticolingüístico». Nunca practicó el silencio, aunque este no callar le creara muchos adversarios y le valiera no pocas descalificaciones rayanas, a veces, en el insulto. Sus reflexiones en torno a estas cuestiones eran escuchadas con atención, porque eran fruto de sus amplísimos conocimientos sobre la realidad lingüística española y se hallaban sustentadas en la idea de que la principal función de la lengua es la comunicación y de que cuantos más hablantes utilicen una misma herramienta verbal, más amplia, rica, fácil y cómoda será la comunicación entre la gente. Por eso, según él, es necesario defender la unidad y cohesión del español para evitar su fragmentación y la quiebra de la comunicación entre los quinientos millones de hispanohablantes nativos. Tales planteamientos venían frecuentemente acompañados con posiciones poco contemporizadoras hacia el euskera, al que siempre se refería como una koiné y no como una lengua natural, o bastante combativas hacia el sector del catalanismo que pretendía convertir en monolingüe a esta comunidad bilingüe, dando un trato de favor a la lengua propia y, según él, provocando la desatención del español en los ámbitos educativo y administrativo de Cataluña. Muchas de sus opiniones sobre estos temas tuvieron gran impacto y alentaron la polémica, tanto por el tono frontal y apasionado con que él las defendía como por difundirlas en tribunas públicas y en artículos de prensa, de modo que sus argumentos no quedaban recluidos en el ámbito académico, sino que llegaban a un público amplio, informado e interesado.

Acabamos de aludir a su actividad periodística, y no podemos dejar de destacar que fue en estos artículos de prensa donde desplegó todo su ingenio, toda su experiencia humana y su agudeza intelectual en el tratamiento de variados asuntos. Nada humano le fue ajeno, y por sus animadas columnas pasaron temas tan dispares como el lenguaje del deporte, la política educativa, una lectura veraniega, un encuentro con Rita Hayworth, sus oposiciones a catedrático de Enseñanza Media, el recuerdo a la mujer mejor cantada -Josefina Manresa, por su esposo Miguel Hernández-, algún recuerdo familiar y un interminable etcétera. Su estilo directo y su finura expresiva fueron valorados y reconocidos con diversos premios periodísticos, como el Mariano de Cavia o el González Ruano, entre otros.

Pero si brillante fue su papel como articulista, no menos atención merece su faceta de conferenciante, donde cautivaba a su auditorio con su bien hablar y su buen decir. Fue un maestro en el arte de la palabra, y tratara de un tema o de otro, Gregorio Salvador aplicaba a sus conferencias el principio horaciano prodesse et delectare. Dotado de un talento especial para construir un texto oral de párrafo largo, con 
intercalaciones aclaratorias, con el toque de humor y el gracejo natural que nunca faltaban, con anécdotas que venían al caso o con sucesos de la vida común, siempre concitó el interés del público oyente, numeroso y variado. En no pocas ocasiones le escuché, y seguramente en algún lugar lo dejó escrito, que la conferencia era «un ensayo para decir», o sea, no un texto dirigido a un lector individual, sino una reflexión expresada en voz alta a un auditorio. Nunca perdió de vista esa naturaleza de la conferencia como construcción verbal dirigida a un oyente colectivo con el que se mantiene una conversación de tema concreto tratado con exigencia y rigor intelectual. Muy claro tenía, pues, que la conferencia era un subgénero oratorio y didáctico sometido a determinadas leyes internas de construcción y de elocución. Y tan claro lo tenía que, en más de una oportunidad, hizo dos promesas que, desgraciadamente, nunca se cumplieron, que eran poner por escrito los principios que, en su opinión, deben regir la elaboración de este tipo de discursos y pronunciar una "conferencia sobre la conferencia».

Está concluyendo esta evocación de su travesía docente e investigadora, y no citar su labor como profesor de Crítica Literaria y su papel como crítico sería ignorar una importante faceta de su trayectoria, porque, aun a riesgo de que mi opinión no pase de ser una mera impresión personal, sostengo que era en este ámbito de la Crítica y la Estilística donde el doctor Salvador más disfrutaba. Y, si no él, sí, desde luego, sus alumnos, que siempre tuvimos la sensación de que sus intervenciones eran un apasionante viaje por el mundo de los mecanismos y recursos que gobiernan la creación literaria. Lo ayudaba su pasión lectora, su desenfado expresivo, su curiosidad por lo nuevo y su veneración por lo clásico. Gracias a él, se nos hizo familiar el teatro del Siglo de Oro, la novela hispanoamericana y la literatura testimonial, a la que nos hizo llegar a través de los sobrecogedores documentos sobre la antropología de la pobreza contenidos en los libros del norteamericano Oscar Lewis. Su rigor analítico facilitó nuestra aproximación a los recursos estilísticos y a las técnicas constructivas de textos literarios, y por él nos fueron muy familiares escritores como Baroja, Valle-Inclán, Juan Ramón Jiménez, García Lorca, Antonio Machado, Miguel Hernández y su admirado Blas de Otero. Y gracias a sus clases, al año siguiente de su publicación, Cien años de soledad ya era novela conocida por sus alumnos, y él, entre bromas y veras, alardeaba de que ya, a las alturas de 1969, había convertido en clásico a Gabriel García Márquez, porque - decía- «clásico» es el autor que es objeto de estudio en clase. Y vaya si lo fue, porque la lección inaugural del curso 1969-1970 en la Universidad de La Laguna, pronunciada por él, llevaba por título Comentarios estructurales a Cien años de soledad, y pocos meses después impartió una conferencia con el título de Las Islas Afortunadas en Cien años de soledad.

Se nos ha ido un gran profesor, un habitante de un mundo con libros, un centinela del idioma. Murió en su casa un triste 26 de diciembre de 2020, a los 93 ańos, dejando un rastro de reconocimiento en el mundo académico y de dolor entre sus discípulos, a quienes ayudó, animó, asesoró y protegió.

Alumnos o discípulos hay con una mayor y más brillante y dilatada vida universitaria, más atentos a las nuevas tendencias en la investigación semántica o dialectal y, sin duda, mucho más capacitados para ponderar y situar el bagaje científico del doctor Salvador en el marco de la Lingüística actual, pero su evocación 
no va a ser fruto de más afecto, respeto y gratitud que los que expresa quien estas líneas escribe.

Manuel Torres Stinga Academia Canaria de la Lengua 
